\title{
Memahami Teologi Paulus tentang Dosa
}

\author{
Natanael Wasiyona \\ Sekolah Tinggi Teologi Paulus Medan, Sumatera Utara \\ natanaelwsiyona@gmail.com
}

\begin{abstract}
The term in the field of theology which is often discussed and even taken place in the study of religious education is sin. One term that is easy to read but has a fundamental and profound meaning if examined further. Indonesian means sin with a very simple sentence. But if we study sin based on the Greek terminology, the meaning will be very broad and very profound. In this case the terms of sin will be explained by the Apostle of all tribes, the Apostle Paul. The term sin received much and deep attention in the theology of the Apostle Paul. By the Apostle Paul, sin was not just breaking God's law. Therefore an explanation of the terms of sin put forward by the Apostle Paul in Greek terminology and its meaning in depth combined with a discussion of the origin of sin, the universality of sin, and the consequences of sin will be discussed in this paper.
\end{abstract}

Keywords: Paul; sin; theology; Pauline theology

\begin{abstract}
Abstrak: Istilah dalam bidang ilmu Theologia yang kerap diperbincangkan bahkan mengambil tempat dalam kajian pendidikan keagamaan adalah dosa. Satu istilah yang mudah untuk dibaca namun memiliki makna yang mendasar dan mendalam jika dikaji lebih lanjut. Bahasa Indonesia memaknai dosa dengan kalimat yang sangat sederhana. Namun jika kita mengkaji dosa berdasarkan terminologi dalam bahasa Yunani maka maknanya akan sangat luas dan sangat mendalam. Dalam hal ini akan dijabarkan istilah-istilah dosa yang dibahas oleh sang Rasul segala suku bangsa yaitu Rasul Paulus. Istilah dosa mendapat perhatian yang banyak dan mendalam dalam theologia Rasul Paulus. Oleh Rasul Paulus, dosa ternyata tidak hanya sekedar melanggar hukum Tuhan. Oleh sebab itu penjelasan istilah-istilah dosa yang dikemukakan oleh Rasul Paulus dalam terminologi bahasa Yunani dan artinya secara mendalam yang dipadukan dengan pembahasan asal mula dosa, universalitas dosa, dan akibat dosa akan dibahas dalam tulisan ini.
\end{abstract}

Kata kunci: dosa; Paulus; teologi; teologi Paulus

\section{PENDAHULUAN}

Dosa bukanlah kata yang dapat dipahami dengan cara yang sederhana. Dalam Kamus Besar Bahasa Indonesia Edisi Ketiga $^{1}$ dosa diartikan sebagai perbuatan yg melanggar hukum Tuhan atau agama, perbuatan salah (seperti terhadap orang tua, adat, negara). Pembahasan tentang dosa memang akan sangat sederhana jika hanya ditinjau dari arti yang dijabarkan oleh Kamus Besar Bahasa Indonesia, namun akan sangat luas dan memiliki makna yang mendalam jika dikaji dalam sudut pandang theologia Rasul segala bangsa yaitu Rasul Paulus. Istilah dalam bahasa Yunani yang memaknai tentang dosa dibahas

${ }^{1}$ Pusat Bahasa Departemen Pendidikan Nasional, Kamus Besar Bahasa Indonesia Edisi Ketiga, (Jakarta: Balai Pustaka, 2002), 275. 
dengan sangat apik jika kita mempelajari surat-surat Rasul Paulus. Oleh sebab itu tulisan ini akan menjabarkan istilah-istilah dosa dalam terminologi kata bahasa Yunani yang dijabarkan oleh rasul Paulus.

\section{METODE}

Kajian ini menggunakan pendekatan kualitatif literatur dengan metode studi teks dalam Kitab Suci, khususnya Perjanjian Baru. Studi teks Perjanjian Baru ini pun menggunakan metode deskriptif, yang bertujuan untuk memberikan gambaran secara biblikal tentang konsep dosa dalam Bahasa asli, yakni Yunani, agar pembaca kitab suci dalam Perjanjian Baru memperoleh pemahaman yang mendalam mengenai konsep dosa.

\section{Deskripsi Istilah Dosa}

Ada beberapa kata dalam bahasa Yunani yang digunakan oleh rasul Paulus untuk menggungkapkan terminologi kata dosa:

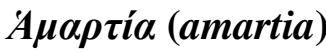

Mengherankan bahwa perkataan yang paling umum untuk dosa baik dalam PL maupun PB berarti "tidak mengenai sasaran" atau "meleset dari sasaran". 2 A $\mu \alpha \tau^{\prime i ́ \alpha}$ (Amartia) adalah kata Yunani yang mewakili arti tersebut. Selain salah tidak mengenai sasaran, Kamus ESword Thayer ${ }^{3}$ mendefinisikan dosa dengan: to miss or wander from the path of uprightness and honour, to wander from the law of God (menyimpang dari jalan, garis kebenaran dan kehormatan, menyimpang dari hukum Tuhan). A $\mu \alpha \rho \tau i ́ \alpha$ (Amartia) ditulis 174 kali di PB, dan 71 di antaranya ada di dalam surat-surat rasul Paulus. Perkataan ini bukan hanya mengenai perbuatan dosa, melainkan juga keadaan hati dan pikiran yang jahat. Perkataan ini berarti manusia ada dalam keadaan ditipu. ${ }^{4}$ Contoh: Rm. 6:23.

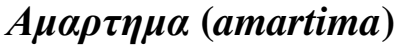

Kata Yunani ini menunjukkan dosa sebagai hasil tindakan, yang berasal dari kata kerja $\alpha \mu \alpha \rho \tau \alpha \nu \omega$ - amartano, "berdosa" atau "berbuat dosa", lebih menitikberatkan pada dosa itu sendiri ketimbang tindakannya sehingga LAI dengan tepat menggunakan awalan ber- di sana. Secara konseptual kata ini berarti "tidak mendapat bagian", "meleset dari sasaran". Contoh. Rm. 3:25; 1Kor. 6:18. Kamus E-Sword Thayer ${ }^{6}$ mendefinisikan dengan: evil deed (perbuatan, tindakan jahat) Kata ini muncul 4 kali di PB dan 2 di antaranya ada di dalam surat-surat rasul Paulus.

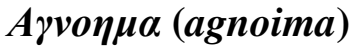

A $\gamma$ vo $\mu \alpha$ (agnoima) artinya adalah kesalahan atau dosa yang disebabkan karena ketidakpedulian. Kata ini berasal dari kata kerja $\alpha \gamma v o \varepsilon \omega$ - agnoeo, diterjemahkan oleh LAI dengan "tidak mengerti", "tidak mengakui" (Kis. 13:27), "tanpa mengenal" (Kis. 17:23).

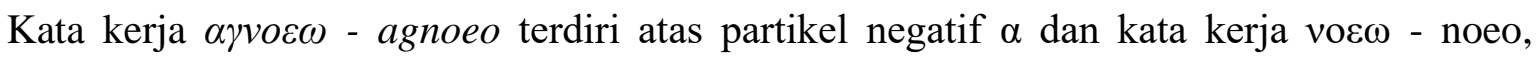

\footnotetext{
${ }^{2}$ J. Wesley Brill, Dasar Yang Teguh, (Bandung: Yayasan Kalam Hidup, 2003), 196.

${ }^{3} e-S w o r d-t h e$ Sword of the LORD with an electronic edge. (E-Sword Thayer)

${ }^{4}$ J. Wesley Brill, 196-197

${ }^{5} \mathrm{http}: / / \mathrm{www}$.sarapanpagi.org/dosa-definisi-vt294.html

${ }^{6} e$-Sword - the Sword of the LORD with an electronic edge. (E-Sword Thayer)
} 
"mengerti", "memahami" dan berhubungan dengan "pikiran". Jadi, jika Allah menghendaki seseorang "memahami" kehendak-Nya tetapi orang tadi mengabaikan, tidak mengindahkannya, tidak mengetahui, maka ia telah berbuat dosa dalam pengertian

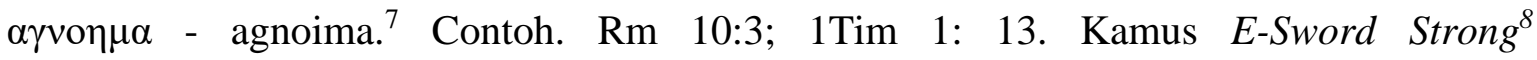

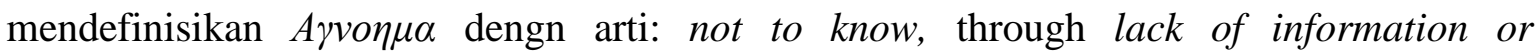
intelligence; by implication to ignore, be ignorant (tidak mengetahui, selalu kekurangan informasi atau kekurangan kecerdasan yang terjadi akibat adanya sikap mengabaikan dan bebal). Orang-orang yang kurang memiliki pengetahuan karena kebebalan hatinya dikategorikan dengan kata ini. Kata ini muncul sebanyak 22 kali dalam PB dan 17 di antaranya ada di dalam surat-surat rasul Paulus.

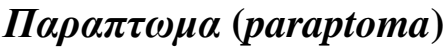

$\Pi \alpha \rho \alpha \pi \tau \omega \mu \alpha$ (paraptoma) artinya "kesalahan", "jatuh dari kondisi yang seharusnya berdiri tegak." Kata $\pi \alpha \rho \alpha \pi \tau \omega \mu \alpha$ - paraptoma berasal dari kata kerja $\pi \alpha \rho \alpha \pi \imath \tau \omega$ - parapipto, artinya "murtad", secara konseptual berarti jatuh di samping seseorang atau benda, terpeleset, menyimpang dari jalan yang benar, berbalik. Kata parapipro sendiri terdiri atas preposisi $\pi \alpha \rho \alpha$ - para, "di samping", dan kata $\pi \imath \tau \omega$ - pipto, "jatuh" dari tempat yang lebih tinggi ke tempat yang lebih rendah, digunakan juga dalam pengertian "sujud menyembah" yaitu menjatuhkan diri dari posisi berdiri menjadi bertelut, tersungkur atau bahkan tengkurep. Kata $\pi \imath \tau \omega$ ini pun digunakan untuk sesuatu (misalnya rumah) yang rubuh diterjang badai, benih yang "jatuh" di pinggir jalan, seseorang yang "jatuh" ke dalam lobang, dan lain-lain. Contoh: Roma 4:25; 5:15-18, 20; 11:11-12 ; 2 Korintus 5:19; Galatia 6:1; Efesus 1:7; 2:1, 5 ; Kolose 2:13. ${ }^{9}$ Dengan demikian boleh juga diartikan sebagai "tidak berdiri teguh pada saat harus teguh", "tidak sampai kepada yang seharusnya". ${ }^{10}$ Kamus $E$ Sword Thayer ${ }^{11}$ mendefinisikan dengan: to fall beside or near something (jatuh di samping atau di dekat sesuatu benda), sementara Kamus E-Sword Strong ${ }^{12}$ mendefinisikan dengan: trespass (penyalahgunaan, masuk tanpa izin). Kata ini muncul sebanyak 23 kali dalam PB dan 16 di antaranya ada dalam surat-surat Rasul Paulus.

\section{П $\alpha \rho \alpha \beta \alpha \sigma \iota \varsigma$ (paravasis)}

Artinya pelanggaran, melewati batas atau garis yang ditentukan, menghancurkan. hukum yang berlaku. Kata $\pi \alpha \rho \alpha \beta \alpha \sigma ı$ berasal dari kata kerja $\pi \alpha \rho \alpha \beta \alpha 1 v \omega$ - paraveno, "melanggar", secara konseptual berarti berjalan melewati garis, seperti para murid Yesus dituduh "melanggar" adat istiadat nenek moyang mereka, dan ungkapan "melangkah keluar" dari ajaran Yesus. ${ }^{13}$ Kamus E-Sword Thayer ${ }^{14}$ juga memberikan arti yang serupa: going over (berjalan di seberang, menyeberang, di luar garis), disregarding (sikap acuh tak acuh).

\footnotetext{
${ }^{7} \mathrm{http}: / / \mathrm{www}$. sarapanpagi.org/dosa-definisi-vt294.html

${ }^{8} e$-Sword - the Sword of the LORD with an electronic edge. (E-Sword Strong)

${ }^{9} \mathrm{http} / / / \mathrm{www}$.sarapanpagi.org/dosa-definisi-vt294.html

${ }^{10}$ J. Wesley Brill, Dasar Yang Teguh, (Bandung : Yayasan Kalam Hidup, 2003), 197.

${ }^{11} e$-Sword - the Sword of the LORD with an electronic edge. (e-Sword Thayer)

${ }^{12} e$-Sword - the Sword of the LORD with an electronic edge. (e-Sword Strong)

${ }^{13} \mathrm{http}$ ://www.sarapanpagi.org/dosa-definisi-vt294.html

${ }^{14} e$-Sword - the Sword of the LORD with an electronic edge. (e-Sword Thayer)
} 
Perkataan ini juga berarti "menyimpang dari yang seharusnya", Perkataan ini selalu dipakai dalam hal pelanggaran terhadap hukum yang pasti. Hukum-hukum Allah menuntut supaya manusia mentaatinya, dan bilamana manusia tidak mau mentaatinya, berarti ia adalah pelanggar hukum dan berdosa, dan murka Allah akan jatuh ke atas dia. ${ }^{15}$ Contoh: Roma 2:23; 4:15; 5:14; Galatia 3:19; 1 Timotius 2:14.

\section{Avouıа (anomia)}

Artinya "kejahatan". Kata $\alpha v o \mu \imath \alpha$ berasal dari kata sifat (adjektiva) anomos yaitu partikel

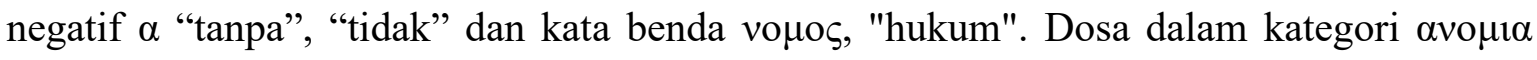
adalah suatu kondisi tanpa hukum karena mengabaikannya atau karena menentangnya. Cth: Roma 4:7; 6:19; 2 Korintus 6:14; 2 Tesalonika 2:7; Titus 2:14. Perkataan ini bukan berarti melanggar hukum dalam suatu perbuatan yang pasti, melainkan dalam hal tidak menurut atau tidak mempedulikan hukum itu. Ini menerangkan tentang keadaan hati. ${ }^{16}$

Menerangkan kata Avoul , Kamus E-Sword Strong ${ }^{17}$ memakai kata illegality, iniquity, transgress of law yang artinya adalah ketidahsahan, ketidakadilan, melewati melampaui batas-batas hukum, sedangkan Kamus E-Sword Thayer ${ }^{18}$ menjelaskan arti Avoula dengan kalimat: the condition of without law because ignorant of it (suatu keadaan tanpa hukum yang dikarenankan kebodohan, kedunguan atau kebebalan). Kata Avo $\mu$. ditulis sebayang 17 kali dalam PB dan ada 6 di antaranya tertulis dalam surat Rsul Paulus.

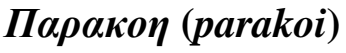

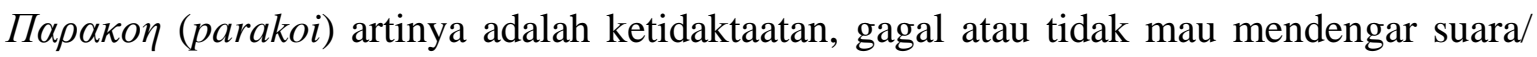

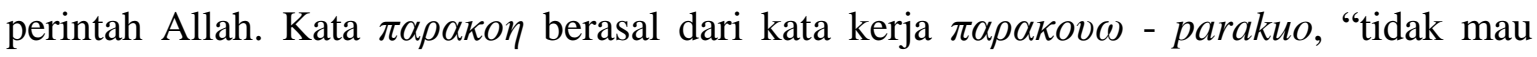
mendengarkan" (Matius 18:17), tidak bersedia mendengar, tidak memperhatikan, menolak mendengar. Secara konseptual, $\pi \alpha \rho \alpha \kappa o \eta$ secara langsung bermakna "gagal mendengar", atau mendengar tanpa perhatian. Kata kerja $\pi \alpha \rho \alpha \kappa o \eta$ terdiri atas preposisi $\pi \alpha \rho \alpha-$ para, "di

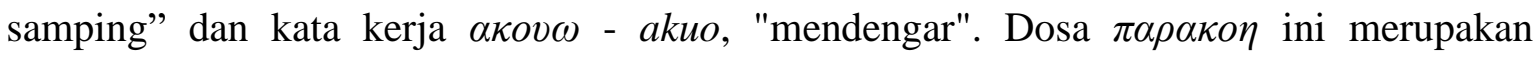
kegagalan mendengar perkataan Allah, dan juga dalam makna ketidaktaatan yang aktif. Contoh: Roma 5:19; 2 Korintus 10:6; Ibrani 2:2. ${ }^{19}$ Kamus E-Sword Strong ${ }^{20}$ memberikan

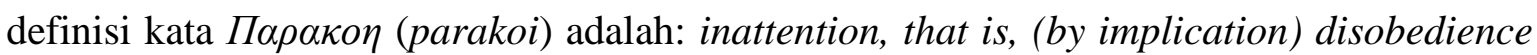
(kurang perhatian, sebagai implikasi dari tidak mematuhi, ketidaktundukan, pengabaian

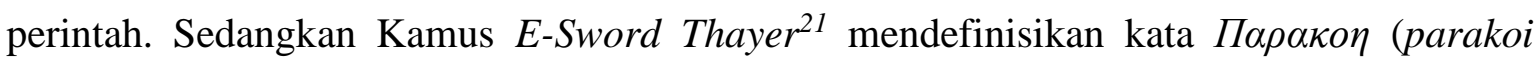
sebagai a hearing amiss (keliru, salah mendengar). Kata ini muncul sebanyak 3 kali dalam PB dan 2 di antaranya ada dalam surat Rasul Paulus.

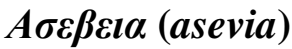

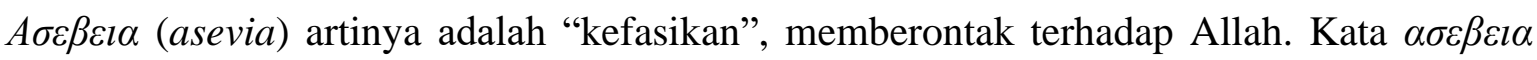
berasal dari kata sifat $\alpha \sigma \varepsilon \beta \eta \varsigma$ - asevis, yaitu gabungan dari partikel negatif $\alpha$ dan kata kerja

\footnotetext{
${ }^{15}$ J. Wesley Brill, Dasar Yang Teguh, (Bandung : Yayasan Kalam Hidup, 2003), 197.

${ }^{16} \mathrm{http}: / / \mathrm{www}$.sarapanpagi.org/dosa-definisi-vt294.html

$17 e$-Sword - the Sword of the LORD with an electronic edge. (e-Sword Strong)

${ }^{18} e$-Sword - the Sword of the LORD with an electronic edge. (e-Sword Thayer)

${ }^{19}$ Ibid. http://www.sarapanpagi.org/dosa-definisi-vt294.html

${ }^{20} e$-Sword - the Sword of the LORD with an electronic edge. (e-Sword Strong)

${ }^{21} e$-Sword - the Sword of the LORD with an electronic edge. (e-Sword Thayer)
} 
$\sigma \varepsilon \beta \omega$ - sevo, "menyembah", jadi secara konseptual, bermakna "tidak mau menyembah", "tidak mau tunduk". Dosa $\alpha \sigma \varepsilon \beta \varepsilon l \alpha$ ini merupakan suatu keadaan membentuk oposisi langsung terhadap Allah, semua kata ini diterjemahkan dengan "kefasikan" dalam Perjanjian Baru Indonesia. Contoh: Roma 1:17-18; 11:26; 2 Timotius 2:16; Titus 2:12. ${ }^{22}$ Kata ini juga berarti keadaan fasik, tidak ber-Tuhan. Kata ini mengandung arti bahwa tabiatnya berlawanan dengan tabiat Allah. ${ }^{23}$

Kamus E-Sword Strong ${ }^{24}$ memberikan definisi A $\sigma \varepsilon \beta \varepsilon \imath \alpha$ (asevia) dengan arti: impiety (sikap tidak menghormati), wickedness (Kejahatan, kenakalan), ungodly (tidak beriman),

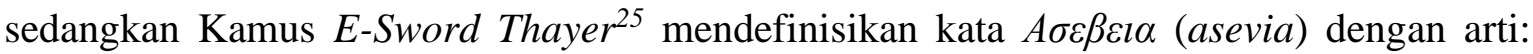
wan't of reverence towards God (tidak menghormati Tuhan). Kata ini muncul sebanyak 7 kali dalam PB dan 4 di antaranya muncul dalam surat Rasul Paulus.

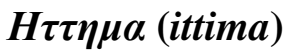

$\mathrm{H} \tau \tau \eta \mu \alpha($ ittima) artinya adalah "keburukan", kegagalan dalam tugas dan kewajiban. Kata Yunani $\eta \tau \tau \eta \mu \alpha$ berjenis nomina (kata benda), dibentuk dari kata kerja (verba) $\eta \tau \tau \alpha \omega$ - ittao, diterjemahkan oleh LAI dengan "dikebelakangkan" (2 Korintus 12:13). Masih ada kata yang asalnya sama yaitu $\eta \tau \tau o v$ - itton dan kata ini berjenis adjektiva, diterjemahkan oleh LAI dengan "keburukan" (1 Korintus 11:17), mungkin terjemahan "lebih buruk" agak cocok), dan "kurang dikasihi" (2 Korintus 12:15). Jika seseorang diharuskan melakukan "sepuluh" kewajiban, namun ternyata ia hanya melakukan "empat", atau kurang dari "sepuluh", maka ia melakukan "dosa" dalam pengertian $\eta \tau \tau \eta \mu \alpha .{ }^{26}$ Kamus E-Sword

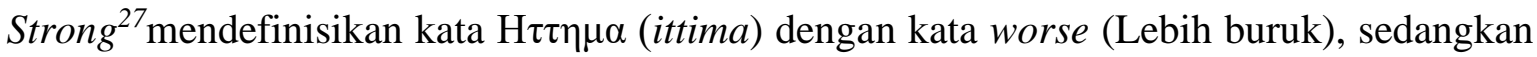
Kamus E-Sword Thayer ${ }^{28}$ mendefinisikan kata H $\tau \tau \eta \mu \alpha$ (ittima) dengan kata inferior (kelas bawah). Kata ini hanya muncul sebanyak 2 kali dalam surat Rasul Paulus.

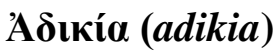

Alkitab Terjemahan Baru mendefinisikan kata $\dot{\alpha} \delta$ ikí (adikia) dengan kata kelaliman.

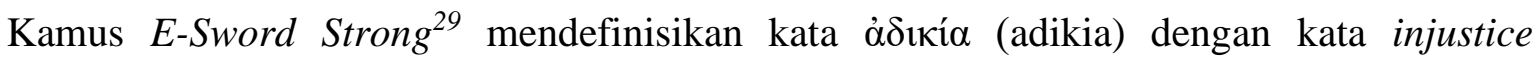
(ketidakadilan), moral wrongfulness (kebobrokan moral), sedangkan Kamus E-Sword Thayer ${ }^{30}$ mendefinisikan kata $\alpha \delta$ เ ${ }^{\prime} \alpha$ (adikia) sebagai injustice of a judge (Ketidakadilan yang ditunjukkan leh seorang hakim), unrighteousness of heart and life (Ketidakbajikan hati dan hidup). Kata ini muncul sebanyak 25 kali dalam PB dan 13 di antaranya ada dalam surat Rasul Paulus.

\footnotetext{
${ }^{22}$ Ibid. http://www.sarapanpagi.org/dosa-definisi-vt294.html

${ }^{23}$ J. Wesley Brill, Dasar Yang Teguh, (Bandung : Yayasan Kalam Hidup, 2003), 197.

${ }^{24} e$-Sword - the Sword of the LORD with an electronic edge. (e-Sword Strong)

${ }^{25} e$-Sword - the Sword of the LORD with an electronic edge. (e-Sword Thayer)

${ }^{26} \mathrm{http}: / / \mathrm{www}$. sarapanpagi.org/dosa-definisi-vt294.html

27 -Sword - the Sword of the LORD with an electronic edge. (e-Sword Strong)

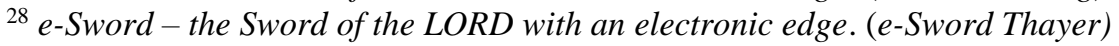

${ }^{29} e$-Sword - the Sword of the LORD with an electronic edge. (e-Sword Strong)

${ }^{30} \mathrm{e}-\mathrm{S}$ word - the Sword of the LORD with an electronic edge. (e-Sword Thayer)
} 


\section{PEMBAHASAN}

\section{Asal Mula Dosa}

Ada beberapa hal yang dapat diutarakan sehubungan dengan asal mula dosa, yakni:

\section{Dosa tidak berasal dari Allah}

Alkitab tidak memberikan tempat untuk Allah dipandang bertanggung jawab atas dosa. Mengenai hal ini, satu hal yang dapat kita lihat dari Alkitab adalah satu ijin yang misterius untuk munculnya kejahatan sebagai akibat dari salah penggunaan akan kebebasan yang diciptakan di dalam makhluk-makhluk rohani, yang juga menjadi aspek dari gambar dan rupa Allah dan juga menjadi fondasi penting bagi moralitas, tetapi yang harus dipertanggungjawabkan pada keadilan dan penghakiman Allah. Dosa tidak berasal dari Allah. Dalam Alkitab hanya terdapat sedikit keterangan tentang asal mula dosa. 2 Tesalonika 2:7 mengatakan bahwa kedurhakaan itu bekerja secara rahasia. Louis berpendapat bahwa merupakan suatu penghujatan jika kita mengatakan bahwa Allah adalah pembuat dosa. ${ }^{31}$

\section{Dosa berasal dari dunia Malaikat}

Alkitab menerangkan bahwa dosa berasal dari suatu makhluk yang mempunyai kehendak bebas, yaitu Lucifer. Pada mulanya Lucifer adalah seorang malaikat terang yang agung dan suci. Lucifer telah memberontak serta mendurhaka kepada Allah, tetapi sebabnya kita tidak tahu. Hanya ada sedikit keterangan dalam Alkitab mengenai sebab dosa dalam diri si Setan, yaitu kesombongan. Dosa berasal dari kehendak Setan. Tuhan Allah telah menjadikan malaikat-malaikat dengan kehendak yang bebas, dan hal itu akan menjadi baik asal dipimpin dengan baik. Jadi rupanya dosa mulai ada ketika Iblis mendurhaka kepada Allah.

Dalam Yesaya 14:12-17 diterangkan bahwa Bintang Timur, putera Fajar, telah jatuh dari langit karena mendurhaka kepada Allah. Perhatikan perkataan "aku hendak" yang diulang lima kali dan akhirnya "aku hendak menyamai Yang Mahatinggi!" (ayat 14). Bandingkan hal itu dengan 2 Tesalonika 2:4 di mana Antikristus, wakil Iblis, akan mengaku dirinya sebagai Allah. "Menurut penafsiran Alkitab secara umum, makhluk pertama yang dianugerahi kehendak bebas adalah malaikat-malaikat. Dan dengan demikian, maka asal mulanya dosa dalam alam ini disebabkan makhluk yang bebas kehendaknya itu salah memilih. Memang dosa harus berasal dari makhluk yang bebas kehendaknya, sebab kalau tidak, dosa tidak menjadi dosa, hanya suatu kesalahan atau nasib. Itulah asal mula jatuhnya beberapa malaikat ke dalam dosa. Dosa mengubah mereka sehingga mereka menjadi setan dan roh-roh jahat. Yang menjadi penghulunya ialah Lucifer, yang paling mendurhaka kepada Allah."

Jadi, rupanya dosa telah timbul di dalam Bintang Timur itu ketika kehendaknya menyimpang pada jalan yang salah, yaitu melawan Allah. Pada waktu beberapa malaikat

${ }^{31}$ Louis Berkhof, Teologi Sistematika Jilid 2-Doktrin Manusia, (Surabaya : Penerbit Momentum, 2009), 89 . 
berdosa, tidak semua malaikat ikut berdosa. Keadaan ini tidak sama dengan dosa Adam yang mendatangkan dosa ke atas segenap manusia. ${ }^{32}$

\section{Asal mula dosa dalam umat manusia}

Ini juga yang diajarkan Paulus kepada kita dalam Rm. 5:12, "Sebab itu sama seperti dosa sudah masuk ke dalam dunia oleh satu orang, dan oleh dosa itu juga maut, demikianlah maut itu telah menjalar kepada semua orang, karena semua orang telah berbuat dosa." Kalimat terakhir itu berarti bahwa mereka semua telah berdosa di dalam Adam dan berdosa dengan cara sedemikian sehingga menjadikan mereka layak untuk dihukum mati. Dosa itu bukan semata-mata dianggap sebagai kekotoran, tetapi juga sebagai kesalahan yang membawa penghukuman. Allah memutuskan bahwa seluruh manusia adalah orang berdosa di dalam Adam, sama halnya dengan la memutuskan bahwa semua orang percaya menjadi benar dalam Yesus Kristus. Inilah yang dimaksudkan oleh Paulus ketika ia berkata: "Sebab itu sama seperti oleh satu pelanggaran satu orang beroleh penghukuman demikian pula oleh satu perbuatan kebenaran semua orang beroleh pembenaran untuk hidup. Jadi sama seperti oleh kctidaktaatan satu orang semua orang telah menjadi orang berdosa, demikian pula oleh ketaatan satu orang semua orang menjadi orang benar." (Rm. 5:18,19). ${ }^{33}$

Dengan demikian dosa itu masuk karena empat hal: ${ }^{34}$

1. Karena tertipu (1 Tim. 2:14)

2. Karena tidak taat kepada hukum Allah (Rm. 5:19)

3. Karena mendengar bujukan si ular (Kej. 3:1-6)

4. Karena Iblis menggoda dan merusak (Why. 12:9)

Boleh dikatakan bahwa dosa muncul dari ciptaan itu sendiri, baik malaikat-malaikat yang jatuh maupun manusia.

\section{Universalitas Dosa}

Rasul Paulus dengan jelas mengatakan bahwa dosa bersifat universal Rm. 3:1-12, 19-23, 5:12-14; Gal. 3:22. Dalam Efesus 2:3 Rasul Paulus berkata bahwa mereka oleh natur mereka adalah anak-anak yang dimurkai, dosa adalah sesuatu yang asli yang dilakukan semua manusia dan menjadikan mereka bersalah di hadapan Allah. bahkan lebih lanjut Rasul Paulus berargumen bahwa maut dialami bahkan oleh mereka yang tidak pernah melakukan suatu pilihan pribadi yang dilakukan dengan sadar Rm. 5:12-14. Ayat ini mengandung pengertian bahwa dosa ada pada bayi-bayi sebelum mereka memiliki kesadaran moral ${ }^{35}$

\section{Akibat Dosa}

Dalam surat-suratnya, Rasul Paulus memberikan keterangan yang jelas tentang akibat dari dosa yang diuraikan secara singkat dalam bagian-bagian berikut:

\footnotetext{
32 J. Wesley Brill, Dasar Yang Teguh, (Bandung : Yayasan Kalam Hidup, 2003), 193-194.

${ }^{33}$ Berkhof, Teologi Sistematika Jilid 2-Doktrin Manusia, 90-91.

${ }^{34}$ J. Wesley Brill, Dasar Yang Teguh, 194.

${ }^{35}$ Berkhof, Teologi Sistematika Jilid 2-Doktrin Manusia, 132.
} 


\section{Manusia Diperbudak}

Dosa adalah tiran keji yang masuk ke dalam dunia dan memanacangkan tonggak kekuasaannya melalui pelanggaran Adam dan Hawa (Rm. 5:12-21), dan sejak itu telah menawan seluruh umat manusia dalam perbudakan yang mengerikan (Rm. 3:9; Gal. 3:22). ${ }^{36}$ Sejatinya manusia diciptakan sebagai makhluk penyembah dan tujuan penciptaan manusia adalah menjadikan manusia sebagai makhluk penyembah Allah. Namun dosa sudah membelokkan kodrat manusia sebagai penyembah Allah menjadi penyembah dosa (iblis). Hal ini berakibat sadar atau tidak sadar manusia secara alamiah memiliki potensi berbuat dosa. Tujuan dosa adalah mendapatkan kesetiaan yang tak terbagi dari keseluruhan pribadi. ${ }^{37}$ Sejak dosa pertama, manusia dijadikan hamba dosa. Berdasarkan penciptaan, tubuh adalah sepenuhnya milik Allah, tetapi akibat kejatuhan manusia dalam dosa, tubuh menjadi hamba dosa. Tubuh dosa adalah tubuh di bawah kuasa dosa. ${ }^{38}$ Perhambaan dosa tidak melepaskan kita dari tanggung jawab pribadi. Diri tidak melawan, melainkan rela tunduk kepada serangan dosa. Melalui pikiran kita yang menindas kebenaran dan kehendak kita yang tidak mau taat, dosa tegak berdiri mempertahankan keunggulannya. Tubuh secara rela memberi diri (menyerahkan anggota-anggota tubuh) untuk menjadi hamba dosa (Rm. 6:13; 7:23). ${ }^{39}$

\section{Murka Allah}

Dosa Mendatangkan hukuman Allah atas manusia. Konsep Paulus yang paling radikal dan paling menyeluruh untuk menunjukkan akibat dosa adalah murka Allah (Rm. 5:9, 2:5; Ef. 5:6; Kol. 3:6; 1Tes 1:10). ${ }^{40}$ Rasul Paulus tidak menyamakan murka Allah dengan balas dendam yang tidak terkontrol dan mengabaikan norma. Meskipun Paulus kerap memakai murka dalam pengertian absolute (Rm. 5:59; 12:19; 1Tes 2:16), kita jangan mengartikan murka Allah sebagai kuasa yang beroperasi secara bebas atau personifikasi dari karya jahat yang mendatangkan malapetaka, yang tidak lagi berada di bawah kendali Allah. Sebaliknya murka Allah diarahkan oleh keadilan dan kekudusan-Nya (Rm. 2:5; band. ay. 2, 11; 3:5). Datangnya murka Allah merealisasikan sanksi yang Ia kenakan bagi pelanggaran hukum-Nya yang kudus (Gal. 3:10). ${ }^{41}$

Secara theologies murka Allah dinyatakan dengan rusaknya relasi antara Allah dan manusia, yang bukan sekadar penarikan diri dari persekutuan dengan Allah, tetapi merupakan suatu keterasingan (Kol. 1:21, band. Ef. 2:12; 4:18) dan permusuhan yang bukan hanya dalam arti kejahatan manusia adalah perseteruan dengan Allah (Rm. 8:7; Kol. 1:21), tetapi juga bahwa bagi manusia, Allah telah menjadi musuh mereka (Rm. 5:10; 11:28) dan akibar dari ini semua adalah kematian, upah dosa dalam arti yang paling luas

${ }^{36}$ J. Knox Chamblin, Paulus Dan Diri Ajaran Rasuli Bagi Keutuhan Pribadi, (Surabaya: Momentum, 2009), 42

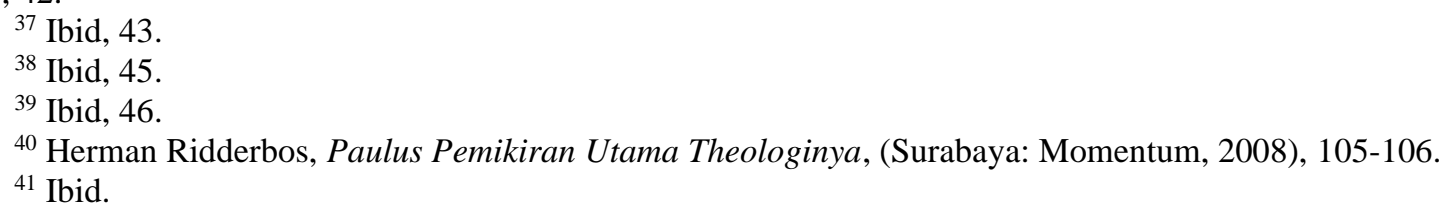


(Rm. 6:23). ${ }^{42}$ Kematian bukan sekadar hukuman yang mengakhiri kehidupan tetapi kondisi yang memutarbalikkan nasib manusia yang hidup di luar Kristus (Gal 6:8; Rm. 9:22; Flp. 3:19; Rm 2:8), terpisah dari kehidupan sejati bagi Allah ( $\mathrm{Rm} 6: 11$ ) dank arena itu dipimpin menuju kematian (Rm. 6:16). Inilah yang Paulus sebut dengan terjual di bawah kuasa dosa (Rm. 7). ${ }^{43}$

\section{KESIMPULAN}

Setidaknya ada 10 kata dalam bahasa Yunani yang dipakai oleh Rasul Paulus untuk menjelaskan dan memaknai kata dosa dan pelanggaran akan hukum Allah. Tulisan Rasul Paulus sangat gamblang menjelaskan tentang akibat dari dosa dan sifat dosa yang universal. Dengan demikian setiap orang yang percaya kepada Tuhan Yesus dibekali dengan pemahaman yang mendalam untuk menghindar dan melawan kuasa dosa.

\section{REFERENSI}

Alkitab. Jakarta: Lembaga Alkitab Indonesia, 2009.

Amplified Bible. e-Sword - the Sword of the LORD with an electronic edge. Strong Definition.

Amplified Bible. e-Sword - the Sword of the LORD with an electronic edge. Thayer Definition.

Berkhof, Louis. Teologi Sistematika Jilid 2-Doktrin Manusia. Surabaya: Momentum, 2009.

Brill J. Wesley. Dasar Yang Teguh. Bandung : Yayasan Kalam Hidup, 2003.

Chamblin J. Knox. Paulus Dan Diri Ajaran Rasuli Bagi Keutuhan Pribadi. Surabaya: Momentum, 2009.

http://www.sarapanpagi.org/dosa-definisi-vt294.html

Pusat Bahasa Departemen Pendidikan Nasional. Kamus Besar Bahasa Indonesia Edisi Ketiga. Jakarta: Balai Pustaka, 2002.

Ridderbos Herman. Paulus Pemikiran Utama Theologinya. Surabaya: Momentum, 2008.

${ }^{43}$ Ibid., 111. 